\section{POS1238 ANTIPHOSPHOLIPID ANTIBODIES AND COVID-19: TREND OVER TIME}

S. Mancuso ${ }^{1}$, S. Truglia ${ }^{1}$, A. Capozzi ${ }^{2}$, F. Pasquali ${ }^{1}$, S. Recalchi ${ }^{2}$, G. Riitano ${ }^{2}$, F. R. Spinelli ${ }^{1}$, M. Sorice ${ }^{2}$, R. Misasi ${ }^{2}$, C. Alessandri ${ }^{1}$, C. M. Mastroianni ${ }^{3}$, F. Conti'. ${ }^{1}$ Sapienza University of Rome, Dipartimento di Scienze Cliniche Internistiche, Anestesiologiche e Cardiovascolari, Rome, Italy; ${ }^{2}$ Sapienza University of Rome, Dipartimento di Medicina Sperimentale, Rome, Italy; ${ }^{3}$ Sapienza University of Rome, Dipartimento di Sanità Pubblica e Malattie infettive, Rome, Italy

Background: Since the beginning of the SARS-CoV-2 outbreak, antiphospholipid antibodies ( $\mathrm{aPL}$ ), a known thrombotic risk factor, have been studied in COVID-19 patients, in whom thromboembolic events have been associated with poor prognosis. To date, the pathogenetic role of aPL and the trend over time is still unknown.

Objectives: Aim of the study was to investigate whether aPL positivity was correlated with thrombosis in COVID-19 patients and whether it was a transient or persistent.

Methods: We included all consecutive COVID-19 patients hospitalized at Policlinico Umberto I, Sapienza University of Rome from April 1, 2020 to June 7,2020 . In these patients, serum levels of anti-cardiolipin (aCL) IgM, IgG, IgA, anti- $\beta 2$ glycoprotein I (a $\beta 2 \mathrm{GPI}) \operatorname{IgM}$, IgG were measured by enzyme-linked immunosorbent assay (ELISA) and Lupus Anticoagulant (LA) was detected with coagulatory tests in patients not in treatment with anticoagulant drugs.

Results: Five out of $73(6.8 \%)$ patients resulted positive for $\mathrm{aCL} \operatorname{IgM}, 3$ of them also tested positive for aß2GPI IgM. aCL IgA were tested positive in 14 out of 46 patients (30.4\%). Overall 18 patients resulted positive for at least one test. Seven $(9.6 \%)$ patients developed thrombotic events during hospitalization, 3 of them resulting positive for aPL (Table 1. below).

We observed that patients showing double positivity for $\mathrm{aCL}$ IgM and a $\beta 2 \mathrm{GPI}$ $\operatorname{lgM}$ had a likelihood positive ratio of 6.3 for thrombotic events $(p=0.012)$ and a likelihood positive ratio of 4.9 for increased $D$-dimer levels $(p=0.027)$. aCL IgA, the most prevalent aPL in this cohort, was not associated with thrombosis. Of the $18 \mathrm{aPL}$ positive patients, 5 died, 3 were lost to follow-up, and 10 were tested on a second occasion at least 12 weeks, two patients confirmed positivity without clinical signs suggestive of APS.

Conclusion: These results suggest that double positivity for $\mathrm{aCL}$ and aß2GPI IgM increases the risk of thrombosis in COVID-19 patients, unlike aCL IgA. APL positivity may be persistent and it is advisable to monitor it over time.

Disclosure of Interests: None declared

DOI: 10.1136/annrheumdis-2021-eular.3199

\section{POS1239 \\ POSITIVE IMPACT OF THE FIRST LOCKDOWN IN PATIENTS WITH CHRONIC INFLAMMATORY RHEUMATISM}

C. Gaujoux-Viala ${ }^{1,2}$, C. Traverson ${ }^{1}$, E. Filhol ${ }^{1,2}$, C. Daien ${ }^{3,4}$, S. LaurentChabalier $^{5}$, B. Combe ${ }^{3,4}$, C. Lukas ${ }^{2,3}$, J. Morel ${ }^{3,4}$, C. Hua ${ }^{1,2} .{ }^{1}$ Nîmes University Hospital, Rheumatology, Nîmes, France; ${ }^{2}$ University of Montpellier, IDESP, UMRINSERM, Montpellier, France; ${ }^{3} \mathrm{CHU}$ Lapeyronie, Rheumatology, Montpellier, France; ${ }^{4}$ University of Montpellier, -, Montpellier, France; ${ }^{5}$ Nimes University Hospital, BESPIM, Nîmes, France

Background: Since the beginning of 2020, the COVID-19 pandemic has caused a considerable amount of fear, worry and concern in the general population and among certain groups such as the elderly, healthcare providers and people with pre-existing conditions in particular. Our patients suffering from chronic inflammatory rheumatism (CIR), a group of autoimmune pathologies treated by immunosuppressant medication, are particularly concerned. Actions taken - particularly quarantine and its effects on the normal activities, habits or livelihoods of many people - also have a significant impact. There is little information on the impact of the lockdown in patients with CIR with data measured prospectively, in a standardized way, before and during the first lockdown period.

Objectives: The objective of this ancillary study was to evaluate the psychological impact of the first lockdown period (anxiety, depression, sleep disorders, catastrophizing...) as well as the evolution of disease activity in patients suffering from CIR.

Methods: At two French university hospitals, adult patients with rheumatoid arthritis (RA) according to the ACR-EULAR 2010 criteria, spondyloarthritis (SpA) fulfilling the ASAS 2009 criteria and psoriatic arthritis (PsA) according to the Caspar 2006 criteria were consecutively included in the Catastrophism in Chronic Inflammatory Rheumatism (CRIC) study from September 2019. Sociodemographic data, information on the disease and its treatments were collected as well as questionnaires on disease activity (DAS28, CDAI, BASDAI), function (HAQ), quality of life (SF12, EQ5D), anxiety and depression (HADS, GAD7), insomnia (ISI) and catastrophizing scores (PCS). These data were collected prospectively at baseline, 3, 6 and 12 months.

In this ancillary study, data from patients with an assessment before and during lockdown were analyzed. Statistical analyses were descriptive with a paired Student's T-test.

Results: In all, 140 patients (49 RA, 69 SpA and 22 PsA) were evaluated before and during lockdown. The median age was 53.5 [44-63] years and $60.7 \%$ were women; 74 patients $(53.2 \%)$ were professionally active and 102

Table 1. Clinical and demographic features of the 7 Covid-19 patients that presented thrombotic events

\begin{tabular}{|c|c|c|c|c|c|c|c|}
\hline Features & Patient 1 & Patient 2 & Patient 3 & Patient 4 & Patient 5 & Patient 6 & Patient 7 \\
\hline Age - yr & 67 & 78 & 83 & 43 & 70 & 74 & 95 \\
\hline Sex & female & female & female & male & male & female & male \\
\hline Medical History & $\begin{array}{l}\text { Malignancy, } \\
\text { Hypertension }\end{array}$ & Stroke & $\begin{array}{l}\text { Chronic obstructive } \\
\text { pulmonary } \\
\text { disease }\end{array}$ & $\begin{array}{l}\text { No medical } \\
\text { history }\end{array}$ & $\begin{array}{l}\text { Chronic obstructive } \\
\text { pulmonary disease, } \\
\text { Hypertension }\end{array}$ & Malignancy, & Hypertension \\
\hline \multicolumn{8}{|l|}{ Initial findings } \\
\hline Signs and symptoms & Dyspnea & Dyspnea & Dyspnea & $\begin{array}{l}\text { Fever, } \\
\text { ageusia/ } \\
\text { anosmia, } \\
\text { chest pain }\end{array}$ & Fever, cough & Dyspnea & Dyspnea \\
\hline HRCT chest: Bilateral & yes & yes & yes & yes & yes & yes & yes \\
\hline \multicolumn{8}{|l|}{ ground glass opacity } \\
\hline Lymphocyte & 220 & 210 & 2330 & 1580 & 1680 & 600 & 1390 \\
\hline \multicolumn{8}{|l|}{ count, cells $\times 10^{6} / \mathrm{L}$} \\
\hline Lactate & 223 & 321 & 199 & 227 & 226 & 349 & 199 \\
\hline \multicolumn{8}{|l|}{ dehydrogenase, U/L } \\
\hline Ferritin mcg/L & 614 & 317 & 213 & 387 & 462 & 2455 & 197 \\
\hline D-dimer mcg/L & 730 & 1213 & 2912 & 282 & 688 & 1298 & 1097 \\
\hline PaO2:FIO2, mm Hg & 132 & 120 & 442 & 534 & 348 & 493 & 314 \\
\hline $\begin{array}{l}\text { Anticoagulant therapy at the } \\
\text { time of the thrombotic event }\end{array}$ & $\begin{array}{c}\text { Therapeutic } \\
\text { dosage }\end{array}$ & Prophylactic dosage & Prophylactic dosage & $\begin{array}{l}\text { Not adminis- } \\
\text { tered }\end{array}$ & Therapeutic dosage & Therapeutic dosage & $\begin{array}{c}\text { Therapeutic } \\
\text { dosage }\end{array}$ \\
\hline Thrombotic events & Stroke & Pulmonary embolism & $\begin{array}{l}\text { Peripheral venous } \\
\text { thrombosis }\end{array}$ & $\begin{array}{l}\text { Myocardial } \\
\text { infarction }\end{array}$ & Pulmonary embolism & $\begin{array}{l}\text { Myocardial infarction, peripheral arterial } \\
\text { thrombosis, peripheral venous thrombosis }\end{array}$ & $\begin{array}{l}\text { Peripheral } \\
\text { venous } \\
\text { thrombosis }\end{array}$ \\
\hline Antiphospholipid antibodies & negative & $\begin{array}{l}\text { Anti-cardiolipin IgM low } \\
\text { title, anti- } \beta 2 \text { glicopro- } \\
\text { tein I IgM low title }\end{array}$ & negative & negative & negative & $\begin{array}{l}\text { Anti-cardiolipin IgM low title, anti- } \beta 2 \text { glicopro- } \\
\text { tein I IgM low title }\end{array}$ & $\begin{array}{l}\text { Anti-cardiolipin } \\
\text { IgA low title }\end{array}$ \\
\hline Outcome & Exitus & Exitus & Suicide & Discharged & Discharged & Discharged & Exitus \\
\hline $\begin{array}{l}\text { Antiphospholipid antibodies } \\
\text { tested after at least } 12 \text { weeks }\end{array}$ & NP & NP & NP & NP & NP & Negative & NP \\
\hline
\end{tabular}

